SNAP REACTOR HANDBOOK -

TRANSIENT ANALYSIS

AEC Research and Development Report

\title{
ATOMICS INTERNATIONAI
}

A DIVISION OF NORTH AMERICAN AVIATION, INC. 


\section{DISCLAIMER}

This report was prepared as an account of work sponsored by an agency of the United States Government. Neither the United States Government nor any agency Thereof, nor any of their employees, makes any warranty, express or implied, or assumes any legal liability or responsibility for the accuracy, completeness, or usefulness of any information, apparatus, product, or process disclosed, or represents that its use would not infringe privately owned rights. Reference herein to any specific commercial product, process, or service by trade name, trademark, manufacturer, or otherwise does not necessarily constitute or imply its endorsement, recommendation, or favoring by the United States Government or any agency thereof. The views and opinions of authors expressed herein do not necessarily state or reflect those of the United States Government or any agency thereof. 


\section{DISCLAIMER}

Portions of this document may be illegible in electronic image products. Images are produced from the best available original document. 
This report was prepared as an account of Government sponsored work. Neither the United Stotes, nor the Commission, nor any person acting on behalf of the Commission:

A. Makes any warranfy or representation, express or implied, with respect to the accuracy, completeness, or usefulness of the information contained in this report, or that the use of any information, apparatus, method, or process disclosed in this report may not infringe privately owned rights; or

B. Assumes any liabilities with respect to the use of, or for damages resulting from the use of information, apparatus, method, or process disclosed in this report.

As used in the above, "person acting on behalf of the Commission" includes any employee or contractor of the Commission, or employee of such contractor, to the extent that such employee or contractor of the Commission, or employee of such contractor prepares, disseminates, or provides access to, any information pursuant to his employment or contract with the Commission, or his employment with such contractor. 


\section{SNAP REACTOR HANDBOOK -}

TRANSIENT ANALYSIS

By

W. A. RHOADES

W. B. GREEN

\section{ATOMICS INTERNATIONAL}
A DIVISION OF NORTH AMERICAN AVIATION, INC. P.O. BOX 309
CANOGA PARK, CALIFORNIA

CONTRACT: AT(11-1)-GEN-8

ISSUED: JUL 151964 


\section{DISTRIBUTION}

This report has been distributed according to the category

"Reactor Technology" as given in "Standard Distribution Lists for Unclassified Scientific and Technical Reports" TID-4500 (29th Ed.), April 1, 1964. A total of 655 copies was printed.

NAA -SR -9368 
I. Introduction $\ldots \ldots \ldots \ldots \ldots \ldots \ldots \ldots \ldots \ldots \ldots \ldots \ldots \ldots \ldots \ldots$

II. Basic Reactor Kinetics Equations .............. 7

A. Kinetics of a Bare Reactor ............... 7

B. Reflected Reactor Model.................... 9

C. Normalized Equations................... 11

III. Analytical Solutions of the Basic Reactor Kinetics

Equations ........................... 15

A. Constant Reactivity ................... 15

B. Prompt-Jump Approximation .............. 15

IV. Feedback Effects ................... 17

A. Changes in Reactor Structure and Composition ........ 17

B. Fuel Temperature Changes ................ 17

C. Grid Temperature ........................ 19

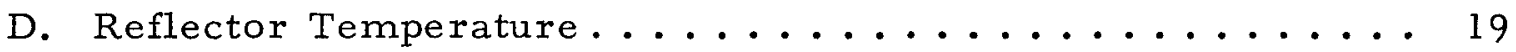

E. Hydrogen Escape ................... 20

F. Calculation of Feedback Effects ............. 20

V. Analytical Solutions of the Kinetics Equations with Temperature Feedback ................... 23

A. High Reactivity Transients ................ 23

B. Low Reactivity Transients ............... 25

VI. Computer Solutions of the Kinetics Problem . . . . . . . . . 27

A. Summary of Available Codes ............... 27

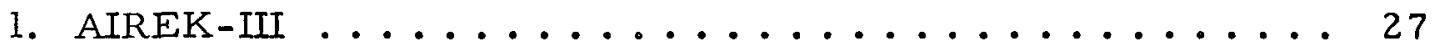

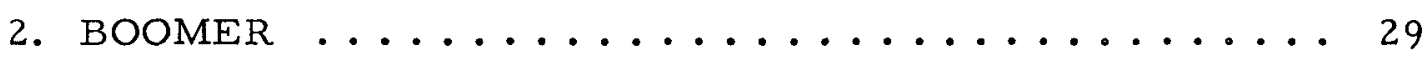

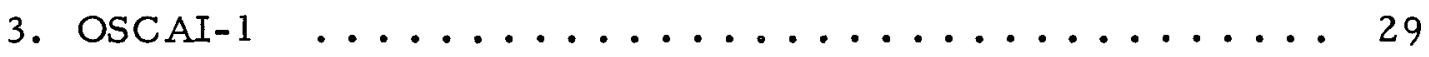

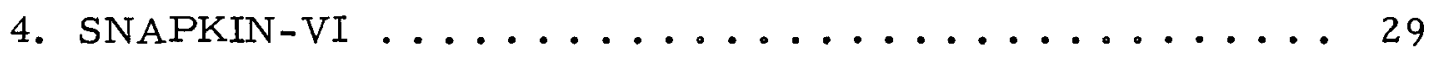

B. Mathematical Methods .................. 29

VII. Typical Data and Transients ................. 31

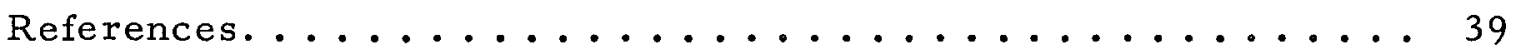




\section{TABLE}

1. Mathematical Models Employed by Various Kinetics Codes . . . . . 28

\section{FIGURES}

1. Neutron Flow Diagram for the Basic Reactor Kinetics

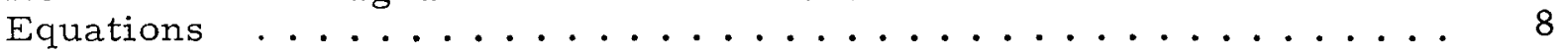

2. Neutron Flow Diagram for the Reflected Reactor Kinetics

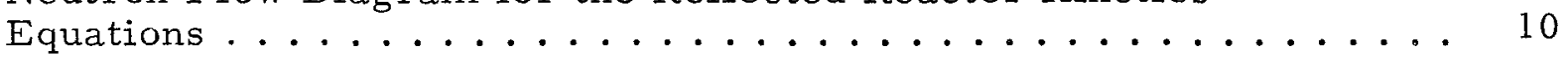

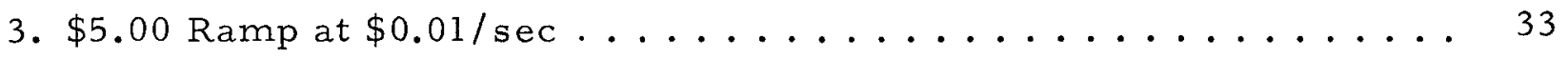

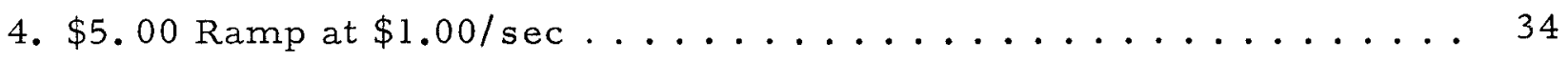

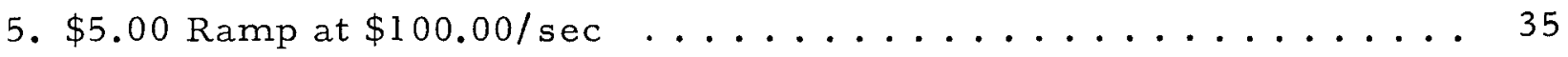

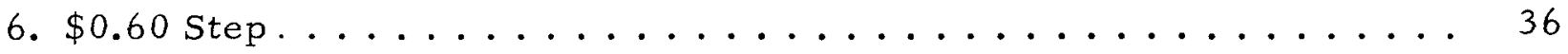

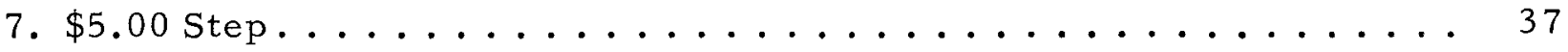




\section{INTRODUCTION}

This report discusses some of the problems involved in the kinetics of uncontrolled power transients in SNAP reactors, and some of the techniques available for solving them. The discussion is oriented toward a basic SNAP design, as typified by a small epithermal reactor with a cylindrical core approximately $12 \mathrm{in.} \mathrm{high} \mathrm{by} 8 \mathrm{in}$. in diameter, moderated by zirconium hydride fuel rods and fueled with fully enriched $U^{235}$ dispersed in the zirconium hydride. It has, typically, a 3-in. beryllium reflector about the radial surface, and is bare at the ends. The coolant is sodium-potassium alloy and is pumped through the interstices between the fuel rods.

The report includes a review of space-independent kinetics equations for bare and reflected reactors, the more important feedback effects present in SNAP reactors, analytical solutions to the equations applicable in certain special cases, and a review of the computer codes available for solution of the equations in the general case. 
Blank page 


\section{BASIC REACTOR KINETICS EQUATIONS}

\section{A. KINETICS OF A BARE REACTOR}

The general behavior of the neutron flux in a reactor is, of course, described by the Boltzmann transport equation. Its dimensionality, seven, makes it quite intractable in this form, and so a simpler model must be chosen for practical calculation. The simplest approximation to this equation which may be used for transient analysis is the common space-independent one-group reactor kinetics model (point reactor model). This model follows from the assumption that the time behavior of the neutron flux in a reactor may be considered independent of the spatial and energy flux distributions. The equations for this model may be written:

Neutron density:

$$
\frac{\mathrm{d}}{\mathrm{dt}} \mathrm{N}=(\mathrm{K}-1-\mathrm{K} \beta) \frac{\mathrm{N}}{\ell^{*}}+\sum \lambda_{i} \mathrm{C}_{i}+\mathrm{S}
$$

Delayed neutron precursors:

$$
\frac{\mathrm{dC}_{i}}{\mathrm{dt}}=\beta_{i} \mathrm{~K} \frac{\mathrm{N}}{\ell^{*}}-\lambda_{i} \mathrm{C}_{i}
$$

where

$$
\begin{aligned}
N & =\text { neutron density } \\
t & =\text { time } \\
\mathrm{K} & =\text { multiplication factor } \\
\ell^{*} & =\text { prompt neutron lifetime, mean } \\
\beta & =\text { delayed neutron fraction, total } \\
\beta_{i} & =\text { delayed neutron fraction, group } i \\
\lambda_{i} & =\text { delayed neutron decay constant, group } i \\
C_{i} & =\text { delayed neutron precursor density, group } i \\
S & =\text { external neutron source }
\end{aligned}
$$

Equations equivalent to these are obtained by Meghreblian and Holmes ${ }^{1}$ from time-dependent diffusion theory. They also can be obtained directly from the Boltzmann equation. 2 Evaluation of the parameters $\beta, \beta_{i}$, and $\ell^{*}$ is 
discussed by Henry. ${ }^{2}$ The equations can be readily understood by means of a neutron flow diagram (Figure 1). Their applicability to a SNAP reactor depends upon the validity of the assumption that the time behavior can be separated from the space and velocity coordinates. In general, this assumption is valid for slow transients; i.e. for $K-1<K \beta$, and for small, bare reactors. The presence of a reflector complicates this situation, since the lifetime of a neutron which migrates to the reflector as a fast neutron and is subsequently returned to the core as a thermal neutron is many times that of a neutron which remains in the core until it is absorbed. This effect can be important for fast transients, and its rigorous treatment requires a solution of the Boltzmann equation in the time variable, in at least one space variable, and in one velocity variable. This process is expensive and tedious, but is the only suitable way to treat very fast transients in some systems. Fortunately, useful approximations have been developed to treat the reflector effect in certain practical cases without including additional dimensions. These will be discussed in detail. For the typical SNAP system, the reflector effect should be considered for cases where $(K-1) / K>2 \beta$.

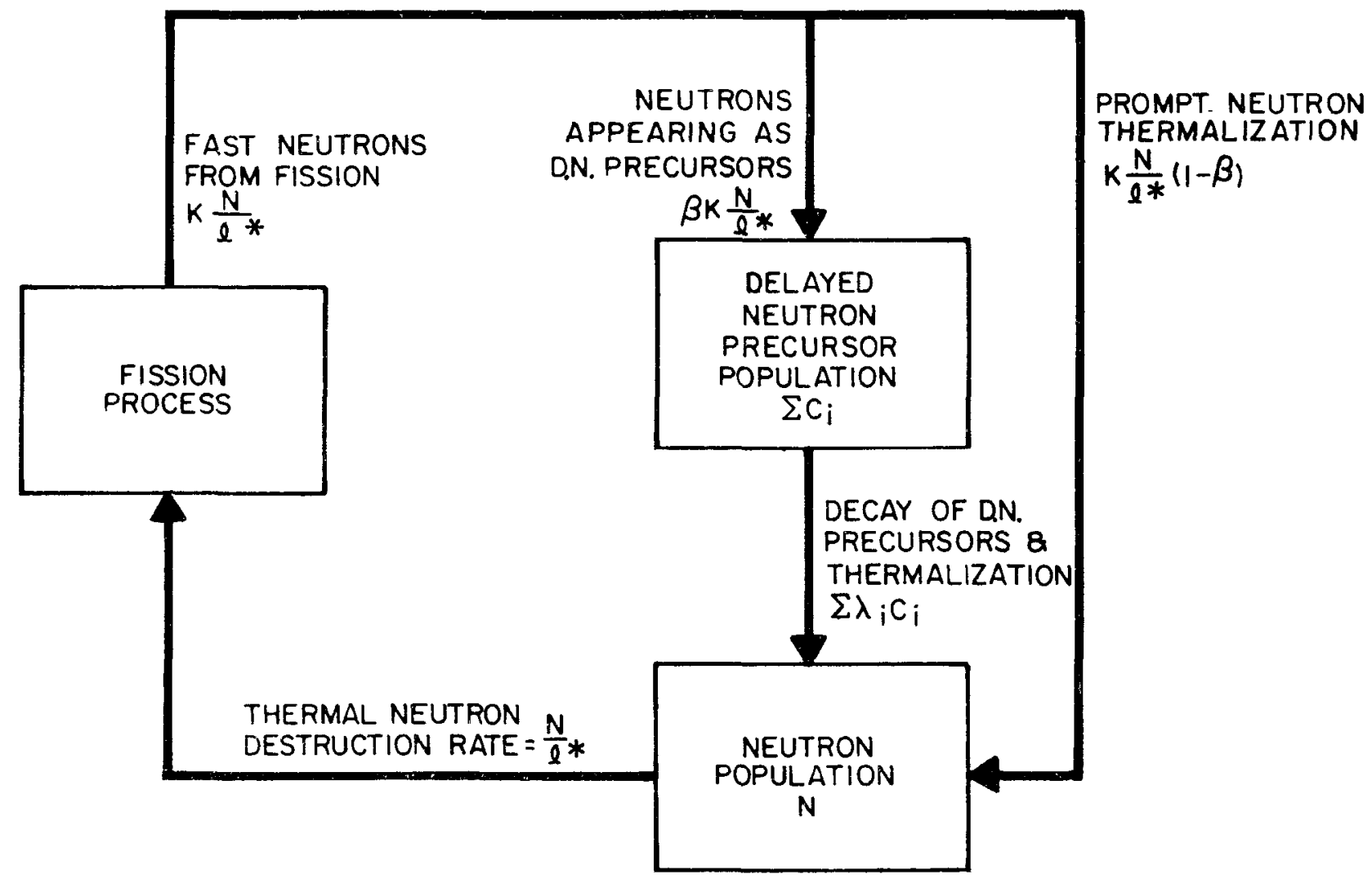

$2-10-64$

7569-01244

Figure 1. Neutron Flow Diagram for the Basic Reactor Kinetics Equations 


\section{B. REFLECTED REACTOR MODEL}

As mentioned above, the calculation of transients in a reflected reactor can be treated by an approximate model which eliminates the requirement for including space dimensions in some calculations.

This model (often called the "s eventh group" or two-node model) assumes that the delay associated with neutrons which leak from the core and are reflected can be represented by a single time constant. $3,4,5$ In SNAP reactors, roughly $40 \%$ of the fission neutrons leak from the core, while about $30 \%$ are returned to the core by the reflector. In the case of a beryllium reflector, approximately $27 \%$ are returned as fast neutrons, with no significant delay involved. The remaining 3\%, which are thermal, do experience a significant delay, and they alone are considered to comprise the reflector group. This idea can also be generalized to several reflector groups, and methods are available for evaluating the required parameters. The model can be represented by a neutron flow diagram (Figure 2) and results in equations such as the following:

Core

neutron

density:

$$
\frac{d N}{d t}=\left[K(1-\beta)\left(1-\beta_{r}\right)-1\right] \frac{N}{\ell_{c}}+\sum_{i} \lambda_{i} C_{i}+\sum_{j} \lambda_{j}^{\prime} C_{j}^{\prime}+S
$$

Delayed

neutron

precursors:

$$
\frac{\mathrm{dC}_{\mathrm{i}}}{\mathrm{dt}}=\beta_{\mathrm{i}} \mathrm{K} \frac{\mathrm{N}}{\ell_{\mathrm{C}}}-\lambda_{\mathrm{i}} \mathrm{C}_{\mathrm{i}}
$$

Reflector

neutrons:

$$
\frac{d C_{j}^{\prime}}{d t}=\beta_{j}^{\prime}(1-\beta) K \frac{N}{\ell_{C}}-\lambda_{j}^{\prime} C_{j}^{\prime}
$$

Mean

lifetime:

$$
\ell^{*}=\ell_{c}+(1-\beta) \sum_{j} \frac{\beta_{j}^{\prime}}{\lambda_{j}^{\prime}}
$$

where

$$
\begin{aligned}
& \ell_{\mathrm{c}}=\text { prompt neutron lifetime, core } \\
& \beta_{\mathrm{r}}=\text { reflector neutron fraction, total } \\
& \beta_{\mathrm{j}}^{\prime}=\text { reflector neutron fraction, } \mathrm{j}^{\text {th }} \text { group }
\end{aligned}
$$




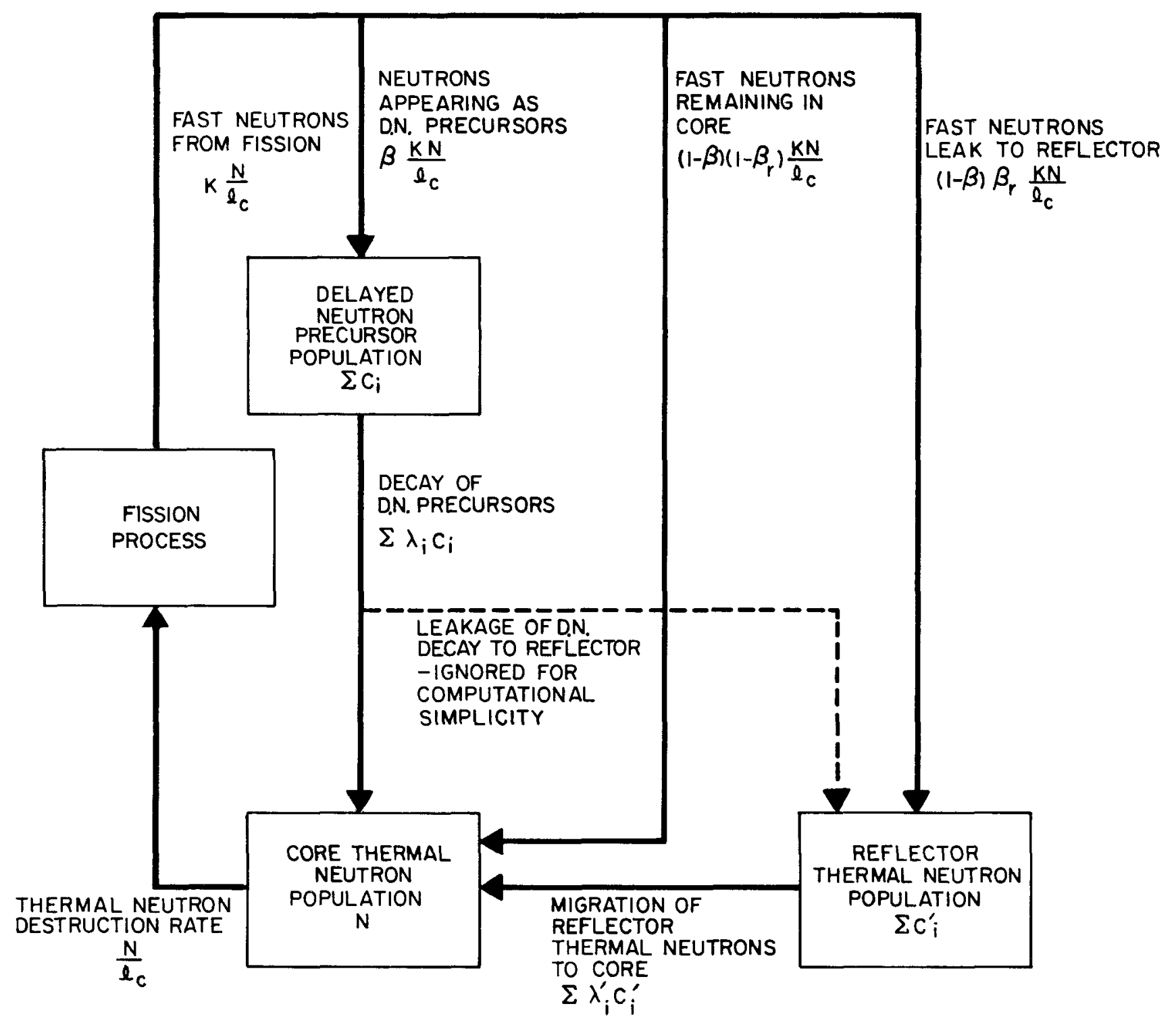

$2-7-64$

$7569-01245$

Figure 2. Neutron Flow Diagram for the Reflected Reactor Kinetics Equations 


$$
\begin{aligned}
& \lambda_{j}^{\prime}=\text { reflector neutron decay constant, } j^{\text {th }} \text { group } \\
& C_{j}^{\prime}=\text { reflector neutron precursor density, } j^{\text {th }} \text { group }
\end{aligned}
$$

From Equation 6, it is clear that we have es sentially broken $l^{*}$ into a short-lived core component, $\ell_{c}$, and longer-lived reflector components with lifetimes $1 / \lambda_{j}{ }_{j}$. Note that a delayed neutron is assumed always to decay into a core neutron. (It might seem better to allow the delayed neutron decay to contribute to both the core and reflector populations. This is a small correction, and one which complicates the equations with very little improvement in the model.)

An additional complication is introduced when the reflector is used to change the value of $K$. In this case, the value of each $\beta_{j}^{\prime}$ changes as $K$ is changed. Miller ${ }^{7}$ has suggested a correction for this:

$$
\beta_{j}^{\prime}=\beta_{j}^{\circ}+\eta\left(\frac{K-1}{K}\right)
$$

where

$$
\begin{aligned}
& \beta_{j}^{\circ}=\text { value of } \beta_{j}^{\prime} \text { for } K=1 \\
& \eta=\text { ratio of } \beta_{r} \text { to total reflector worth }
\end{aligned}
$$

\section{NORMALIZED EQUATIONS}

There is a substitution of variables for the bare reactor kinetics equations which is convenient for both analytical and machine computations. First, reactivity is defined:

$$
r=\frac{(K-1)}{K}
$$

where $r$ can be expressed in units of the (dimensionless) delayed neutron fraction, $\beta$ : 


$$
\rho=\frac{r}{\beta}=\frac{(\mathrm{K}-1)}{\mathrm{K} \beta}
$$

where

$$
\rho=\text { reactivity, } " \$ \text { units" }
$$

The generation time is substituted for the lifetime (since the lifetime is proportional to $\mathrm{K}$ in transients initiated by changes in absorption or leakage):

$$
\Lambda=\frac{\ell^{*}}{\mathrm{~K}}
$$

where

$$
\Lambda=\text { generation time, total }
$$

The $\beta_{i}^{\prime}$ s are rescaled, and the precursors, source, and core neutron density are scaled to power units:

$$
\begin{gathered}
\alpha_{i}=\frac{\beta_{i}}{\beta} \\
\mathrm{W}_{i}=\frac{\lambda_{i} \ell^{*} \xi}{\mathrm{K} \beta \alpha_{i}} \mathrm{C}_{i} \\
\mathrm{~S}_{\mathrm{O}}=\frac{\ell^{*} \xi}{\mathrm{K} \beta} \mathrm{S} \\
\mathrm{P}=\xi \mathrm{N}
\end{gathered}
$$

where

$$
\begin{aligned}
\alpha_{i} & =\text { relative delayed neutron fraction, } i^{\text {th }} \text { group } \\
W_{i} & =\text { delayed neutron precursor density, } i^{\text {th }} \text { group, power units } \\
S_{0} & =\text { source strength, power linits } \\
\xi & =\text { conversion from neutron density to power } \\
P & =\text { power }
\end{aligned}
$$


Equations 1 and 2 become:

Power:

$$
\frac{d P}{d t}=\left[(\rho-1) P+\sum \alpha_{i} w_{i}+S_{o}\right] \frac{\beta}{\Lambda}
$$

Normalized

precursors:

$$
\frac{d W_{i}}{d t}=\lambda_{i}\left(P-W_{i}\right)
$$

The simplification is apparent.

For the reflected case, Equations 3, 4, 5, and 7 can be similarly treated with the additional substitutions:

$$
\begin{gathered}
W_{i}=\frac{\lambda_{i} \ell_{c} \xi}{K \beta \alpha_{i}} C_{i} \\
S_{o}=\frac{\ell_{c} \xi}{K \beta} S \\
\alpha_{r}=\frac{\beta_{r}}{\beta} \\
\alpha_{j}^{\prime}=\frac{\beta_{j}^{\prime}}{\beta} \\
R_{j}=\frac{\beta_{j}^{\circ}}{K(l-\beta) \beta_{j}^{O}} C_{j}^{\prime} \\
\alpha_{j}^{\circ}=\frac{\ell_{c}}{\beta} \\
K
\end{gathered}
$$


where

$\alpha_{\mathbf{r}}=$ relative reflector neutron fraction, total

$\alpha_{j}^{\prime}=$ relative reflector neutron fraction, $j^{\text {th }}$ group

$\alpha_{j}^{\circ}=$ value of $\alpha_{j}^{\prime}$ for $K=1$

$\mathrm{R}_{\mathrm{j}}=$ reflector neutron precursor density, $\mathrm{j}^{\text {th }}$ group, power units

$\Lambda_{\mathrm{C}}=$ generation time, core

Yielding the following, with Equation 7 incorporated:

Power:

$\frac{d P}{d t}=\left\{\left[\rho-1-(1-\beta)\left(\alpha_{r}^{o}+\eta \rho\right)\right] P+\sum \alpha_{i} w_{i}+(1-\beta) \sum \alpha_{j}^{o} R_{j}+S_{o}\right\} \frac{\beta}{\Lambda_{c}} \ldots(24)$

Delayed

neutron

$\frac{d W_{i}}{d t}=\lambda_{i}\left(P-W_{i}\right)$

precursors:

Reflector

neutrons:

$$
\frac{\mathrm{dR}_{\mathrm{j}}}{\mathrm{dt}}=\lambda,\left[\mathrm{P}\left(1+\frac{\eta \rho}{\alpha_{\mathrm{r}}^{o}}\right)-\mathrm{R}_{\mathrm{j}}\right]
$$




\section{ANALYTICAL SOLUTIONS OF THE BASIC REACTOR KINETICS EQUATIONS}

\section{A. CONSTANT REACTIVITY}

Equations 15 and 16 can be solved semianalytically by Laplace transform methods, in the case where $\mathrm{K}$ is constant. The solution has the form

$$
P(t)=C+P(0) \sum_{j=1}^{N+1}\left(A_{j}+B_{j}\right) e^{s_{j} t}
$$

where the $s_{j}$ 's are the $N_{H}$ roots of the equation

$$
F(s)=\rho-\left[\frac{\Lambda}{\beta}+\sum_{i=1}^{N} \frac{\alpha_{i}}{s+\lambda_{i}}\right] s
$$

$P(0)$ is the initital power, $N$ is the number of delayed neutron groups, and where $C$ and the $A_{j}^{\prime} s$ and $B_{j}^{\prime}$ s are constants which depend on $K, s, \Lambda, \beta_{i}$, and $\lambda_{i}$. This problem can be solved by a computer in a matter of seconds using the RE -135 code. $^{8}$

A similar solution is possible when $\mathrm{K}$ is an arbitrary but known function of time. The code RTS performs this calculation, but it is not available at this facility. 9

\section{B. PROMPT-JUMP APPROXIMATION}

A useful approximation which can be solved by hand is the prompt-jump approximation. This assumes that $\Lambda \ll 1 / \lambda_{i}$ for any $i$, that $0<\rho<1$, that the reactor is at steady-state at some power $P(O)$ and reactivity $\rho_{O}$ at time $t=O$, and that $\rho$ is changed instantly to $\rho_{F}$ at $t=0$. Referring to Equations 15 and 16, at $\mathrm{t}=\mathrm{O}, \quad \sum \alpha_{\mathrm{i}} \mathrm{W}_{\mathrm{i}}(0)=\mathrm{P}(0), \mathrm{dP} / \mathrm{dt}=\mathrm{O}$, and so:

$$
\rho_{0}=-\frac{S_{0}}{P(0)}
$$


The solution of Equation 27 shows that at $t=\mathrm{O}^{+}$, the power increases rapidly to nearly balance Equation 15, while the delayed neutrons do not change so rapidly. Then, approximately,

$$
\mathrm{P}\left(\mathrm{O}^{+}\right) \simeq \frac{\mathrm{P}(0)+S_{0}}{1-\rho_{F}}=\frac{P(0)\left(1-\rho_{0}\right)}{1-\rho_{F}}
$$

The power then approaches exponential behavior:

$$
P(t) \approx A e^{\omega t}
$$

In the case of one delayed neutron group, $\mathrm{A}$ is just $\mathrm{P}\left(\mathrm{o}^{+}\right)$. The reciprocal period, $\omega$, is the single positive root of Equation 28. To find this root, graphs of

$$
\rho(\omega)=\left[\frac{\Lambda}{\beta}+\sum_{i=1}^{N} \frac{\alpha_{i}}{\omega+\lambda_{i}}\right] \omega
$$

are plotted for $\omega>0$. These graphs, inhour curves, give $\omega$ immediately for any $\rho$.

Equation 32 is called the inhour equation. Note that it can also be obtained by assuming Equation 31 as a solution to Equations 15 and 16, then solving for $\rho$. Similar techniques also yield an inhour equation from Equations 24, 25, and 26:

$$
\rho(\omega)=\left[\frac{\Lambda}{\beta}+\sum_{i} \frac{\alpha_{i}}{\omega+\lambda_{i}}+(1-\beta) \sum_{j} \frac{\alpha_{j}^{o}}{\omega+\lambda_{j}^{\prime}}\right]\left[\frac{\omega}{\left.1-\frac{(1-\beta) \eta \omega}{\alpha_{r}^{O}} \sum_{j} \frac{\alpha_{j}^{O}}{\omega+\lambda_{j}^{\prime}}\right]}\right.
$$




\section{FEEDBACK EFFECTS}

\section{A. CHANGES IN REACTOR STRUCTURE AND COMPOSITION}

The power generated in a reactor, if more than a few watts, will produce changes in the reactor structure and composition which affect the value of $\rho$ in Equation 15, which in turn affects the amount of power generated. This is, then, a feedback mechanism which changes the course of a transient through its effect on $\rho$. The changes are described by coefficients of reactivity relating $\rho$ to such physical parameters as fuel temperature, grid plate temperature, etc.

$$
\rho(t)=\rho_{0}(t)+\alpha_{F}\left[T_{F}(t)-T_{F}(0)\right]+\alpha_{G}\left[T_{G}(t)-T_{G}(o)\right]+\ldots
$$

where

$$
\begin{aligned}
& \rho_{\mathrm{O}}=\text { reactivity inserted by drum rotation, etc. } \\
& \mathrm{T}_{\mathrm{F}}=\text { fuel temperature } \\
& \mathrm{T}_{\mathrm{G}}=\text { grid temperature } \\
& \alpha_{\mathrm{F}}=\text { fuel temperature coefficient of reactivity } \\
& \alpha_{\mathrm{G}}=\text { grid temperature coefficient of reactivity }
\end{aligned}
$$

This is, of course, a Taylor series expansion of $\rho$ in the variables $T_{F}$, $\mathrm{T}_{\mathrm{G}}$, etc., and

$$
\alpha_{F} \equiv \frac{\partial \rho}{\partial T_{F}}, \alpha_{G} \equiv \frac{\partial \rho}{\partial T_{G}}, \text { etc. }
$$

\section{B. FUEL TEMPERATURE CHANGES}

Changes in the fuel temperature have several effects on the reactor. Perhaps the most obvious is the expansion of the fuel rods. The cylindrical fuel rods used in SNAP reactors are suspended by pins at the ends and do not touch laterally. The radial expansion of the rods does not increase the core radius, but only forces small amounts of coolant from the core with very little reactivity 
effect. The axial expansion of the rods lengthens the core, however, and also reduces the effective fuel density. The net effect is an increase in fast neutron leakage, giving a coefficient of about $-3 \times 10^{-4} \$ /^{\circ} \mathrm{F}$ in the case of the SDR, for example. 10

The thermal neutron velocity spectrum changes with temperature, reducing the thermal utilization of the fuel. The resulting spectral coefficient is about $-4 \times 10^{-4} \$ 1^{\circ} \mathrm{F}$ in the case of the SDR. 10

These effects are prompt; i.e., they occur immediately, for practical purposes, at the instant of a fuel temperature change. Neither the spectrum nor the fuel density change instantly, of course, and the term "prompt effect" implies only that the delays can be ignored for the reactor being considered. The temperature also increases resonance absorption in $U^{238}$, rare earth poisons (if used) and in certain fission products (Doppler broadening). SNAP reactors have almost no $\mathrm{U}^{238}$, but the poisons and fission products can have a significant effect, depending on the specific reactor design. This effect is a prompt effect.

The heat capacity of the zirconium hydride moderator has an important dependence on temperature, in that it approximately doubles between $0^{\circ} \mathrm{C}$ and $1000^{\circ} \mathrm{C}$. Measurements of the heat capacity have been reported by Tomasch 13 and by Taylor. 12 Tomasch's data extends to $500^{\circ} \mathrm{C}$ and Taylor's to $900^{\circ} \mathrm{C}$. Thus a theoretical model is required to extend calculations beyond $900^{\circ} \mathrm{C}$.

Kittel ${ }^{14}$ recommends a combination of the Debye and Einstein models for a diatomic crystal of this type. The Einstein oscillator, in this approximation, is associated with the hydrogen, while the Debye model is associated with the zirconium lattice vibration. The Debye temperature of zirconium (230 to $270^{\circ} \mathrm{K}$ ) is below the temperatures of interest in SNAP studies, so this component can be considered a constant (fortunately, since the Debye model is the more complicated of the two). The resulting model is

$$
C_{P}=C_{1}+C_{2}\left[\left(\frac{\theta_{e}}{T}\right)^{2} \frac{e^{\theta_{e} / T}}{\left(e^{\theta_{e} / T}-1\right)^{2}}\right]
$$


where

$$
\begin{aligned}
C_{P} & =\text { heat capacity } \\
C_{1} & =\text { empirical constant for zirconium } \\
C_{2} & =\text { empirical constant for zirconium } \\
\theta_{e} & =\text { Einstein temperature for the hydrogen } \\
T & =\text { fuel temperature, absolute scale }
\end{aligned}
$$

This model fits the experimental data with $\theta_{e}=1500^{\circ} \mathrm{K}$, in good agreement with neutron scattering results. It is thought to give a reliable extrapolation to high temperatures and is recommended for use. It does ignore the difference between $C_{P}$ and $C_{V}$, as well as a contribution resulting from the valence electrons of zirconium. It is thought that both effects can be ignored for practical calculations.

\section{GRID TEMPERATURE}

Heat transmitted to the grids by conduction from the fuel rods and from coolant circulation causes them to expand, moving the fuel rods apart. This increases the effective core radius and reduces the effective density. The net effect is a loss of reactivity and a grid temperature coefficient of about $-10 \times 10^{-4} \$ /^{\circ} \mathrm{F}$ in the case of the SDR. 10 Because of the time required for heat transmission from the core or through the coolant channel, this must be considered a delayed, not a prompt, effect.

\section{REFLECTOR TEMPERATURE}

Heat transfer from the core causes expansion of the reflector and its mounting supports. The reflector density is thus reduced, and it is moved farther from the core. The reflector coefficient associated with this is dependent on temperature, but is roughly $-4 \times 10^{-4} \$ /^{\circ} \mathrm{F}$ in the case of the SDR. 10 This is also a delayed effect. 


\section{E. HYDROGEN ESCAPE}

If the fuel temperature increases much beyond $1000^{\circ} \mathrm{F}$ during a transient, the hydrogen in the zirconium hydride moderator begins to leave the fuel, building up high pressure inside the fuel cladding and eventually rupturing the cladding. This results in rapid release of hydrogen, with the rate strongly dependent on fuel temperature and composition. The escape of the hydrogen results in -\$0.50 per percent hydrogen lost. The hydrogen escape is quite endothermic, absorbing about $49 \mathrm{kcal}$ of heat per mole of $\mathrm{H}_{2}$ released. 12

The release rate is not known to the accuracy that one might desire. Some measurements at constant temperature reported by Huffine ${ }^{11}$ appea red to give good results, but they did not extend to temperatures above $1550^{\circ} \mathrm{F}$. This creates an uncertainty as to how high in temperature the se data can be extrapolated. Pulse heating experiments reported by Taylor ${ }^{12}$ went to much higher temperatures, but attempts to measure the mean fuel temperature during the period of rapid hydrogen escape were not successful, and so there is some uncertainty as to the actual temperature involved. Other experiments directed toward measuring a diffusion coefficient for hydrogen have been performed, and theoretical models have been developed to explain the data. The validity of applying these data, or, in fact, any elementary diffusion model, to the rapid decomposition of zirconium hydride fuel at high temperature has yet to be shown conclusively.

Additional complexity is found when the core is filled with coolant, for the hydrogen must force the coolant from the core before escaping, or else must blast the core apart in an explosive manner before it can escape. Some efforts to treat this analytically have been made, but this aspect of the problem is largely unsolved.

\section{F. CALCULATION OF FEEDBACK EFFECTS}

The calculation of the coefficients associated with structural and compositional changes is satisfactorily treated by standard reactor criticality analysis. In practice, the calculation is performed by comparing the criticality of a system perturbed in a given manner with that of an unperturbed system. This calculation also can be performed by a single perturbation theory computation. This is not 
especially advantageous in SNAP calculations, however, since the necessary multigroup, multiregion perturbation computations have not been automated to the same degree as the basic criticality computation.

A basic difficulty which appears here is the spatial distribution of such effects as fuel temperature change, etc. The effect of changing the temperature in a fuel rod near the center of the core is, generally speaking, quite different from producing the same change in a rod at the edge of the core. The statistical weight function found in perturbation theory solves this problem, since we may, for a given perturbation $\Delta \mathrm{T}_{\mathrm{F}}(\overline{\mathrm{r}}, \mathrm{t})$, write

$$
\Delta \rho(t)=\alpha_{F} \frac{\int_{\text {reactor }} I(\bar{r}) \Delta T_{F}(\bar{r}, t) d \bar{r}}{\int_{\text {reactor }} I(\bar{r}) d \bar{r}}
$$

where

$$
\begin{aligned}
\Delta \mathrm{T}_{\mathrm{F}}(\overline{\mathrm{r}}, \mathrm{t}) & =\text { nonuniform temperature perturbation } \\
\mathrm{I}(\overline{\mathrm{r}}) & =\text { statistical weight function } \\
\Delta \rho(t) & =\text { reactivity change due to } \Delta \mathrm{T}_{\mathrm{F}}
\end{aligned}
$$

Note that $\alpha_{F}$ must now be considered the fuel temperature coefficient for uniform temperature changes. If $\Delta T_{F}(\bar{r}, t)$ is considered separable, i. e., if we may write

$$
\Delta T_{F}(\bar{r}, t)=\Delta T_{F r}(\bar{r}) \Delta T_{F t}(t)
$$

then Equation 36 becomes

$$
\Delta \rho(t)=\left[\alpha_{F} \frac{\int I(\bar{r}) \Delta T_{F r}(\bar{r}) d \bar{r}}{\int I(\bar{r}) d \bar{r}}\right] \Delta T_{F t}(t)
$$


and the bracketed portion of Equation 35 becomes an effective temperature coefficient evaluated for the particular profile $T_{F r}(\bar{r})$. The function $T_{F t}(t)$ can be determined by the space-independent energy balance

$$
\frac{d}{d t}\left[C_{p} \Delta T_{F t}(t)\right]=P(t)-H(t)
$$

where

$$
\begin{aligned}
& \mathrm{C}_{\mathrm{p}}=\text { heat capacity } \\
& \mathrm{H}=\text { energy loss resulting from heat transfer, hydrogen loss, etc. }
\end{aligned}
$$

Such effects as variable heat capacity, heat transfer (important for slow transients) and the cooling effect of hydrogen escape make the use of separability (Equation 38) invalid in some problems. In this case, the temperature distribution must be calculated as a function of both space and time, and Equation 36 must be used for the feedback calculation. The distribution of hydrogen concentration changes, etc., is handled on a similar basis. 


\section{ANALYTICAL SOLUTIONS OF THE KINETICS EQUATIONS WITH TEMPERATURE FEEDBACK}

\section{A. HIGH REACTIVITY TRANSIENTS}

A useful solution to the kinetics equations for transients initiated by a step insertion of reactivity $\rho>>1$ is the so-called "Fuchs" or "Fuchs-Nordheim" model, in which an analytical solution is obtained by the approximations of ignoring delayed neutrons and heat conduction (these are reasonable assumptions for $\rho>2$, with the accuracy improving for larger $\rho$ ). A variable heat capacity has been recently added to the model by Scalettar, ${ }^{15}$ making it useful for SNAP hazards studies. The equations solved can be written

$$
\begin{gathered}
\frac{d P}{d t}=\left(\delta k_{p}-\alpha T\right) \frac{P}{\ell} \\
\frac{d T}{d t}=\frac{P}{C_{o}+\gamma T} \\
\delta k_{p}=k-1-k \beta
\end{gathered}
$$

where

$$
\begin{aligned}
\mathrm{P} & =\text { power } \\
\mathrm{t} & =\text { time } \\
\delta \mathrm{k}_{\mathrm{p}} & =\text { excess multiplication factor above prompt critical } \\
\ell & =\text { prompt neutron lifetime } \\
\mathrm{C}_{\mathrm{O}} & =\text { heat capacity at } \mathrm{T}=0 \\
\gamma & =\text { heat capacity slope } \\
\alpha & =\text { temperature coefficient (assumed negative) }
\end{aligned}
$$

Introducing the dimensionless parameter

$$
\sigma=\frac{\alpha \mathrm{C}_{\mathrm{o}}}{\gamma \delta \mathrm{k}_{\mathrm{p}}}
$$


Scalettar obtains a final temperature, $\mathrm{T}$

$$
T_{\infty}=\frac{3}{4} \frac{\delta \mathrm{k} p}{\alpha}\left[(1-\sigma)+\sqrt{(1-\sigma)^{2}+\frac{16}{3} \sigma}\right]
$$

a total energy release of

$$
\mathrm{E}_{\infty}=\frac{3}{4} \mathrm{C}_{\mathrm{o}} \mathrm{T}_{\infty}+\frac{1}{2} \gamma \mathrm{T}_{\infty}^{2}
$$

and a maximum power, $P_{\max }$ of

$$
\mathrm{P}_{\max }=\mathrm{P}_{\mathrm{o}}+\frac{1+3 \sigma}{6 \sigma} \frac{\mathrm{C}_{\mathrm{o}} \delta \mathrm{k}_{\mathrm{p}}^{2}}{\alpha \ell}=\mathrm{P}_{\mathrm{o}} \frac{1+3 \sigma}{6} \frac{\gamma \delta \mathrm{k}_{\mathrm{p}}^{3}}{\alpha^{2} l}
$$

The results for limiting cases of constant and linear heat capacity $(\gamma \rightarrow 0$ and $\mathrm{C}_{\mathrm{O}} \rightarrow 0$, respectively) as well as that of a constant "average" heat capacity $\bar{C}=C_{0}+1 / 2 \gamma T_{\infty}$ have been evaluated:

$\begin{array}{lll} & \frac{\mathrm{T}_{\infty}}{2 \delta \mathrm{k}_{\mathrm{p}} / \alpha} & \frac{\underline{\mathrm{P}}_{\text {max }}-\mathrm{P}_{\mathrm{o}}}{\frac{1}{2} \frac{\mathrm{C}_{\mathrm{o}} \delta \mathrm{k}_{\mathrm{p}}^{2}}{\alpha \ell}} \\ \text { Constant Heat Capacity } & \frac{3}{2} \delta \mathrm{k}_{\mathrm{p}} / \alpha & \frac{1}{6} \frac{\gamma \delta \mathrm{k}_{\mathrm{p}}^{3}}{\alpha^{2} \ell} \\ \text { Linear Heat Capacity } & \frac{1+\sigma}{\sigma} \frac{\mathrm{C}_{\mathrm{o}} \delta \mathrm{k}_{\mathrm{p}}^{2}}{\alpha \ell}\end{array}$


Note that $\mathrm{T}_{\infty}$ can be reduced by as much as $25 \%$, depending on the heat capacity shape. Also of interest is the ratio

$$
R=\frac{P_{m}-P_{o}}{P_{m}^{\prime}-P_{o}}=\frac{3 \sigma+1}{3(\sigma+1)}
$$

where

$$
\begin{aligned}
& \mathrm{P}_{\mathrm{m}}=\text { result using given } \gamma \text { and } \mathrm{C}_{\mathrm{o}} \\
& \mathrm{P}_{\mathrm{m}}^{\prime}=\text { result using } \overline{\mathrm{C}} \text { equivalent to given } \gamma \text { and } \mathrm{C}_{0} .
\end{aligned}
$$

This has limits 1 as $\gamma \rightarrow 0$ and $1 / 3$ as $C_{0} \rightarrow 0$, showing a $67 \%$ change in peak power as a result of choosing a different shape for the temperature coefficient.

\section{B. LOW REACTIVITY TRANSIENTS}

A solution for low reactivity transients which includes the effect of delayed neutrons but ignores heat conduction is presented by Miller, et al. ${ }^{10}$ They solve the kinetics equations in the form

$$
\begin{aligned}
\frac{\ell}{\beta} \frac{d}{d t} P & =\left(\rho_{s}-\alpha_{F} T-1\right) P+\sum \alpha_{i} W_{i} \\
\frac{d}{d t} W_{i} & =\lambda_{i}\left(P-W_{i}\right) \\
\frac{d}{d t} T & =P / C
\end{aligned}
$$

They solve these directly, obtaining

$$
\frac{\ell}{\beta}\left(\mathrm{P}-\mathrm{P}_{\mathrm{o}}\right)=\mathrm{C}\left(\rho_{\mathrm{S}} \mathrm{T}-\frac{1}{2} \alpha_{\mathrm{F}} \mathrm{T}^{2}\right)-\sum \frac{\alpha_{\mathrm{i}}}{\lambda_{\mathrm{i}}}\left(\mathrm{W}_{\mathrm{i}}-\mathrm{W}_{\mathrm{i}}\right)
$$


With the assumption that $W_{i_{0}}=P_{o}$ at $t=0(\theta=0)$ and $W_{i}=P=P_{\max }$ at the time of peak power (this is valid if the reactivity insertion is small), they obtain

$$
\mathrm{P}_{\max } \simeq \frac{1}{2} \frac{\rho^{2} \mathrm{C}}{\alpha_{F}}
$$

and

$$
\theta \text { at time of } P_{\max } \approx \frac{\rho}{\alpha_{F}}
$$

This result is useful for determination of the $\alpha_{F}$ from the peak power obtained in a slow transient with no coolant flow. 


\section{COMPUTER SOLUTIONS OF THE KINETICS PROBLEM}

In Reactor Kinetics, as in most other fields of engineering, high-speed digital computers facilitate the solution of highly complex problems with speed, accuracy, and reliability. A complete hand calculation of a reactor transient, including a detailed treatment of feedback, would be nearly impossible to produce in a reasonable time, but can be done usually in a few seconds of computer time.

The ideal kinetics code for application to SNAP systems would contain the following calculations:

a) Calculation of neutron density (as sumed spatially independent) including effects of reflector delayed neutrons, and photoneutrons when they are important

b) A detailed spatially dependent heat-transfer calculation

c) Calculation of the effects of hydrogen evolution and temperature feedback in the neutron kinetics calculations

d) Calculation of fuel melting, coolant boiling, clad burst, and other mechanical effects.

The ideal code would produce both printed and graphical output, and the type and amount of these would be specified by the user. The input scheme should be straightforward and mathematical techniques should yield the most accurate and reliable result in the least amount of machine time.

\section{A. SUMMARY OF AVAILABLE CODES}

None of the codes currently available at Atomics International contains all of the above mentioned features. The available IBM 7094 codes include:

1. AIREK-III ${ }^{16}$

This code contains a rapid solution of the neutron kinetics equations with simple feedback mechanisms. It is recommended for use where spatially dependent heat transfer effects, hydrogen diffusion effects, etc., are not of interest. Fuel temperature feedback can be simulated by proper assignment of input data (see Table 1).

NAA-SR-9368 
TABLE 1

MATHEMATICAL MODELS EMPLOYED BY VARIOUS KINETICS CODES

\begin{tabular}{|c|c|c|c|c|}
\hline & & AIREK-III & BOOMER & SNAPKIN - VI \\
\hline & Specific Heat & Constant & $\begin{array}{l}\text { Linear Variation With } \\
\text { Temperature }\end{array}$ & $\begin{array}{l}\text { Einstein Oscillator plus } \\
\text { Constant }\end{array}$ \\
\hline \multirow{5}{*}{ 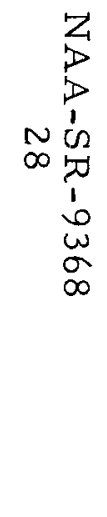 } & Feedback & $\begin{array}{l}\text { Fuel } \\
\text { Temperature }\end{array}$ & $\begin{array}{l}\text { Fuel Temperature, Hydrogen } \\
\text { Loss, } † \text { Grid Temperature } \dagger\end{array}$ & $\begin{array}{l}\text { Fuel Temperature, Hydrogen } \\
\text { Loss }\end{array}$ \\
\hline & Heat Transfer & $\begin{array}{l}\text { Fuel } \\
\text { Temperature }\end{array}$ & $\begin{array}{l}\text { Discretized Diffusion } \\
\text { Equations }\end{array}$ & Newton's Cooling Law \\
\hline & $\mathrm{H}_{2}$ Escape & None & $\begin{array}{l}\text { Discretized Diffusion } \\
\text { Equations }\end{array}$ & $\begin{array}{l}\text { Semi-empirical Exponential } \\
\text { Equation }\end{array}$ \\
\hline & $\begin{array}{l}\text { Coolant Heat } \\
\text { Transfer }\end{array}$ & None & $\begin{array}{l}\text { Discretized Coolant Hydro- } \\
\text { dynamics }\end{array}$ & None \\
\hline & $\begin{array}{l}\text { Grid } \\
\text { Temperature }\end{array}$ & None & Simple Heat Balance & None \\
\hline
\end{tabular}
*For an AIREK run simulating fuel temperature feedback, set $P_{j}=1 / C_{p}, U_{j}=\left[\sigma T_{c} / C_{p} N(0)\right]$, and
$Y_{j}=-\sigma / C_{p}$

$\dagger$ At the present time, these BOOMER options do not appear to function properly ${ }^{18}$ 


\section{BOOMER $^{17}$}

This code incorporates a SNAP-2/10A geometry spatially dependent heat transfer calculation and a hydrogen diffusion model. It simulates the SNAP reactor in considerable detail, but its general use cannot be recommended because of mathematical and numerical difficulties.

3.

Although it contains detailed heat transfer calculations, this code is not suitable for use in design of SNAP systems because it does not treat SNAP geometry.

4. SNAPKIN-VI ${ }^{20}$

This code contains a rapid solution of the neutron kinetics equation, including effects of reflector delayed neutrons, and space independent calculations that give estimates of fuel temperature, hydrogen evolution, and coolant heat removal. Input and output are straightforward, and the user has his choice of the data to be printed and plotted.

\section{B. MATHEMATICAL METHODS}

For the solution of the kinetics equations, SNAPKIN-VI and AIREK-III both use Cohen's method ${ }^{2 l}$ to solve the reactor kinetics equations. This is a modification of the Runge-Kutta method for solution of quasi-linear differential equations, and it produces an accurate and reliable answer in a short amount of machine time in most cases of interest.

BOOMER uses Euler integration ${ }^{22}$ to solve the kinetics equations. This method consumes more machine time and is more prone to numerical instability than is Cohen's method (see Reference 18). The method, when properly applied, does give satisfactory results, however.

Heat transfer models and other mathematical models used to simulate hydrogen diffusion and other effects vary from code to code. Table 1 indicates various models used in AIREK-III, BOOMER, and SNAPKIN-VI. The reader is advised to refer to the particular code writeups for detailed information regarding the models used in each code. 


\section{Blank page}




\section{TYPICAL DATA AND TRANSIENTS}

The following data are considered typical for the basic SNAP design as discussed in the introduction, except that the 3-in. Be reflector is replaced by a 6 -in. $\mathrm{H}_{2} \mathrm{O}$ reflector where indicated. Symbols are as used in preceding discussions.

\begin{tabular}{|c|c|c|}
\hline $\begin{array}{c}\text { Basic Kinetics } \\
\text { Parameters }\end{array}$ & Be Reflected & $\mathrm{H}_{2} \mathrm{O}$ Reflect \\
\hline$\Lambda$ & $7.64 \times 10^{-6} \mathrm{sec}$ & $15.2 \times 10^{-6}$ \\
\hline$\Lambda_{\mathrm{c}}$ & $4.47 \times 10^{-6} \mathrm{sec}$ & $6.09 \times 10^{-6}$ \\
\hline & $139.0 \times 10^{-6} \mathrm{sec}$ & $234.0 \times 10^{-6}$ \\
\hline$\beta_{\mathrm{r}}$ & $2.28 \%$ & $3.9 \%$ \\
\hline$\beta$ & 0.008 & 0.008 \\
\hline$\eta$ & 0.1 & 0.1 \\
\hline \multicolumn{3}{|l|}{$\begin{array}{c}\text { Feedback } \\
\text { Coefficients } \\
\end{array}$} \\
\hline $\begin{array}{l}\text { Prompt Fuel } \\
\text { Total }\end{array}$ & $\begin{array}{r}-7.0 \times 10^{-4} \$ /^{\circ} \mathrm{F} \\
-21.0 \times 10^{-4} \$ /^{\circ} \mathrm{F}\end{array}$ & Not available \\
\hline \multicolumn{3}{|l|}{$\begin{array}{l}\text { Fuel Heat } \\
\text { Capacity } \\
\end{array}$} \\
\hline $\mathrm{C}_{1}$ & 7,000 watt $-\sec ^{\circ} \mathrm{F}$ & Same \\
\hline $\mathrm{C}_{2}$ & 18,700 watt $-\sec ^{\circ} \mathrm{F}$ & as $\mathrm{Be}$ \\
\hline$\theta_{\mathrm{e}}$ & $3,060^{\circ} \mathrm{R}$ & \\
\hline Delayed Neutrons & $\alpha_{i}$ & $\lambda_{i}$ \\
\hline Group 1 & 0.033 & 0.0124 \\
\hline Group 2 & 0.219 & 0.0305 \\
\hline Group 3 & 0.196 & 0.111 \\
\hline Group 4 & 0.395 & 0.301 \\
\hline Group 5 & 0.115 & 1.13 \\
\hline Group 6 & 0.042 & 3.0 \\
\hline
\end{tabular}

Figures 3 through 7 show the transients resulting from reactivity excur sions, as labeled on each graph. These particular results were obtained from the SNAPKIN-VI Code 20 , but are typical of results from the other codes as 
well. Hydrogen loss, conduction to surrounding environment of $2 \mathrm{kw} / 1000^{\circ} \mathrm{F} \Delta \mathrm{T}$, and initial conditions of steady-state operation at 0.01 watt were used.

Figures 3,4 , and 5 show the insertion of $\$ 5.00$ of reactivity as a ramp (i.e., at a constant rate). Figure 3 shows a slow insertion in which the power increases slowly at first, and then rapidly increases to a maximum at $85 \mathrm{sec}$. At this point, the fuel has warmed sufficiently to stop the power rise, and the power begins to drop off because of the increasing fuel temperature. The fuel temperature finally exceeds the cladding failure temperature at $100 \mathrm{sec}$, and rapid hydrogen escape results in complete reactor shutdown.

Figure 4 shows two peaks in power as temperature first rises to stop the power rise at about $1.2 \mathrm{sec}$, reactivity catches up with the temperature and causes power to rise again, and then an additional increase in temperature turns the power back again. The pulsing behavior is terminated after the second peak by hydrogen loss which rapidly shuts down the reactor.

In Figure 5, the power rises very rapidly and is turned back by fuel temperature increase. Cladding failure occurs even before peak power, and rapid hydrogen loss prevents a second peak in this case. Note that the energy releases in these three cases were 32, 50, and $69 \mathrm{Mws,} \mathrm{respectively.} \mathrm{Over} \mathrm{this} \mathrm{range}$ of insertion rates, the energy release, which is a measure of the severity of the transient, increases for faster insertion rates.

In Figure 6, $\$ 0.60$ is inserted as a step (i.e., immediately at time =0). The qualitative behavior and energy release (24 Mws) are roughly comparable to the $\$ 0.01 / \mathrm{sec}$ ramp. Temperature rises to turn back the reactivity, and power falls off. Since reactivity is not continuously inserted in this case, the power falls more rapidly than in the case of a ramp, and cladding failure occurs later.

In Figure 7, a $\$ 5.00$ step is used. Note that this establishes the upper limit to the variation of behavior with ramp rate, corresponding to infinite ramp rate. In this case, power rises quite rapidly and is turned back by a combination of temperature rise and large hydrogen losses. The hydrogen loss then shuts down the reactor. The energy release, $80 \mathrm{Mws}$, is even higher than that for the $\$ 100 / \mathrm{sec}$ ramp, as would be expected. 


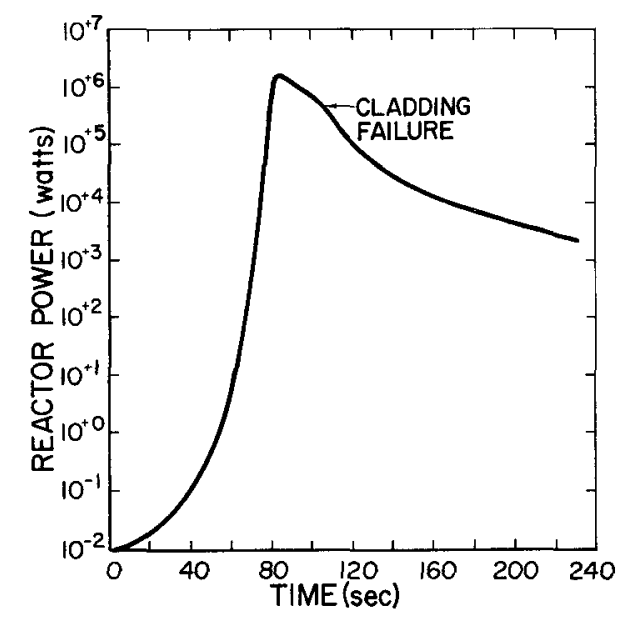

a. Reactor Power

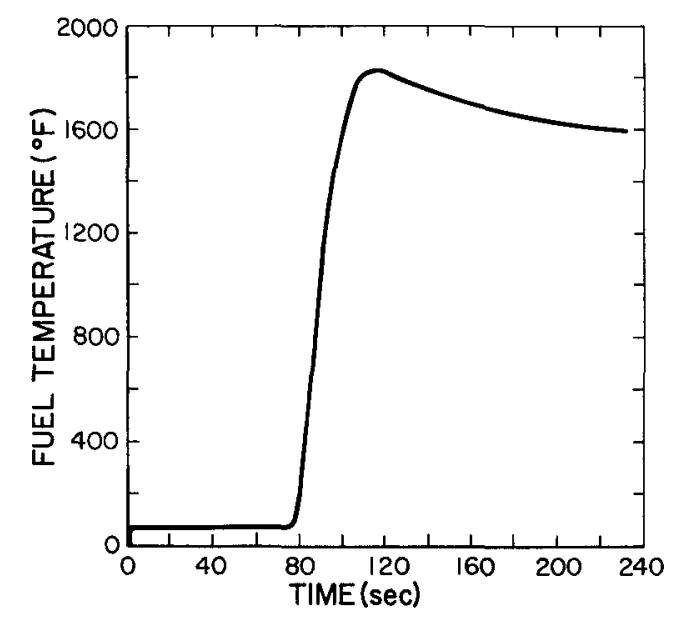

b. Fuel Temperature

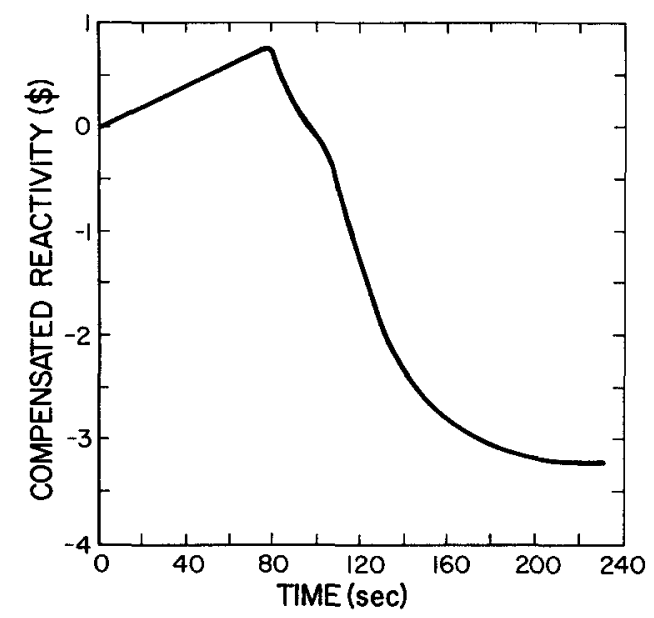

c. Compensated Reactivity

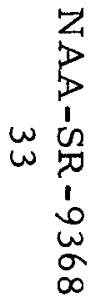

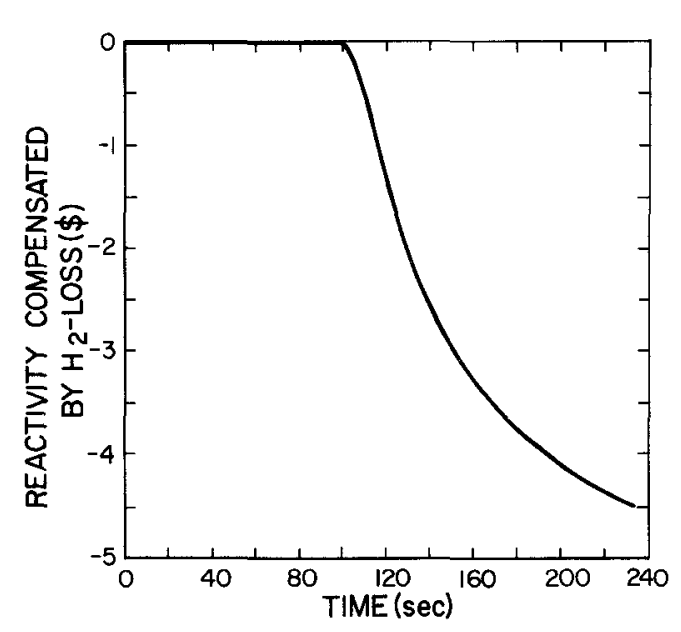

d. Reactivity Compensated

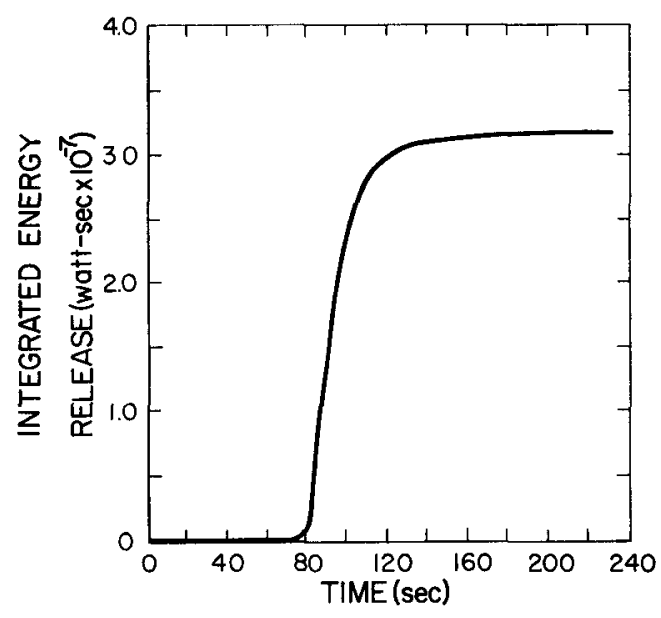

e. Integrated Energy Release

Figure 3. $\$ 5.00$ Ramp at $\$ 0.01 / \mathrm{sec}$ 


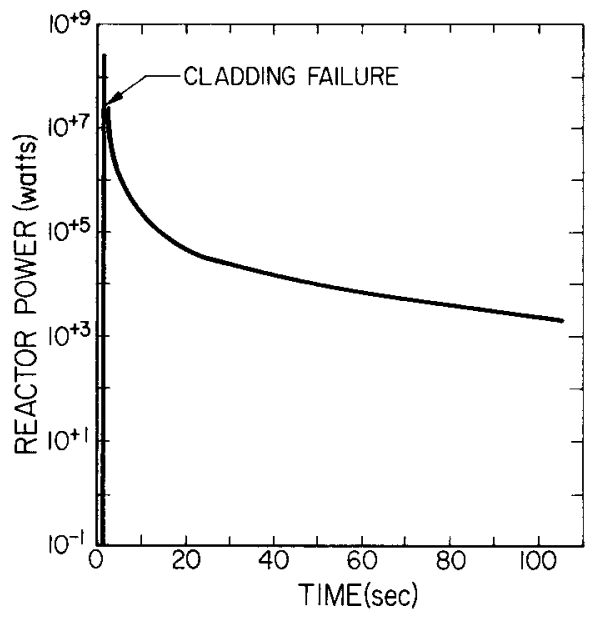

a. Reactor Power

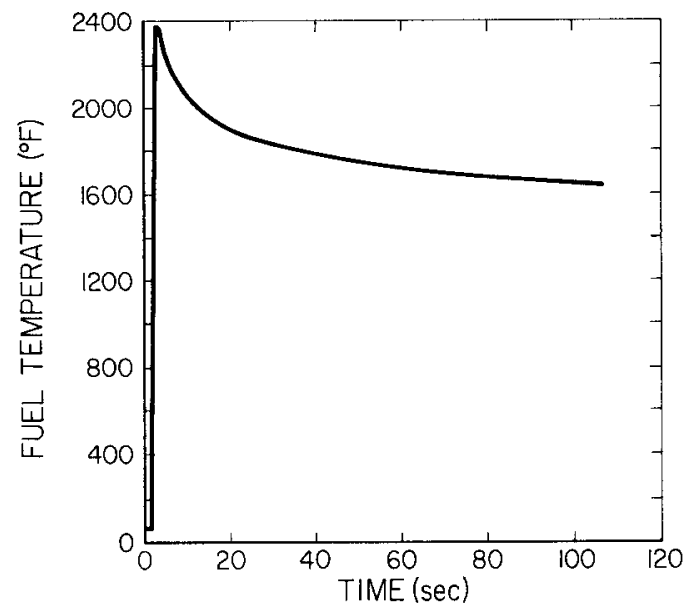

b. Fuel Temperature

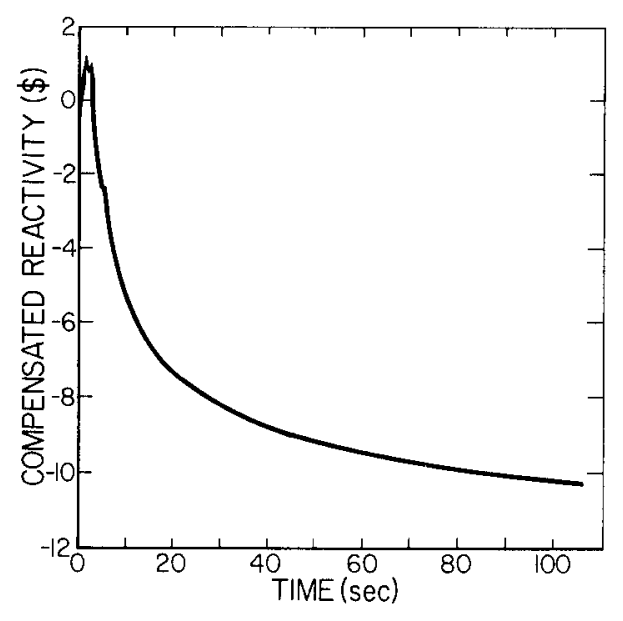

c. Compensated Reactivity

2
3
5
1
1
12
10
1
1
$\omega$
2
$\infty$
$\infty$

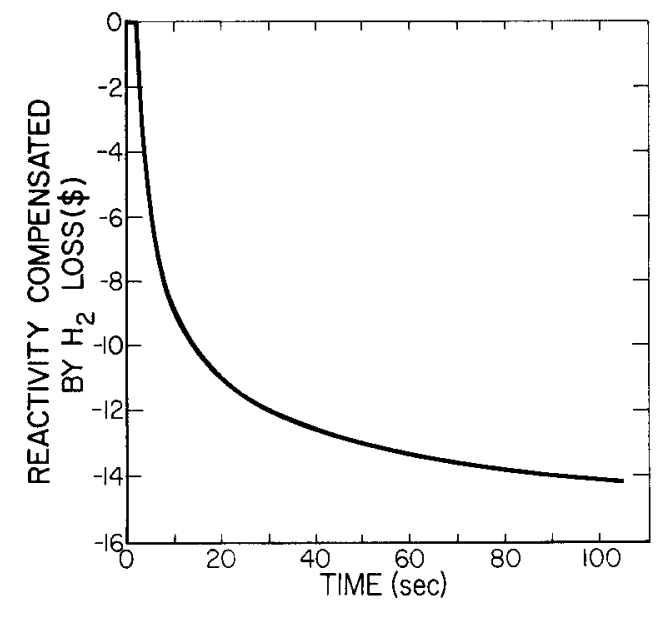

d. Reactivity Compensated by $\mathrm{H}_{2}$ Loss

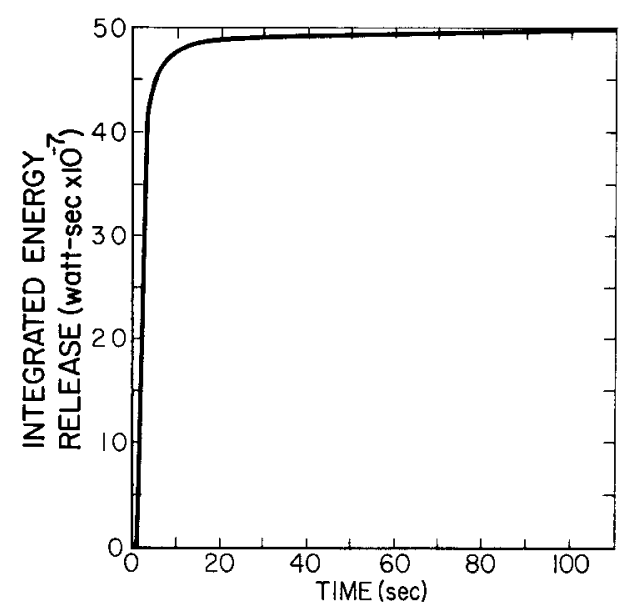

e. Integrated Energy Release

Figure 4. $\$ 5.00 \mathrm{Ramp}$ at $\$ 1.00 / \mathrm{sec}$ 


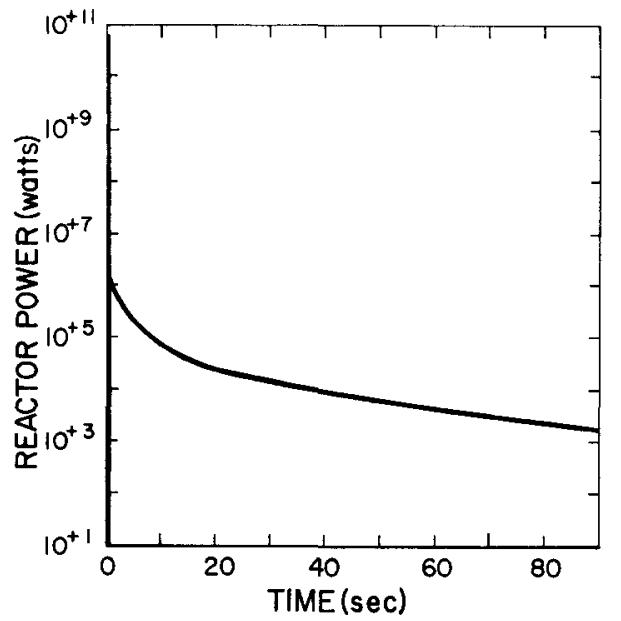

a. Reactor Power

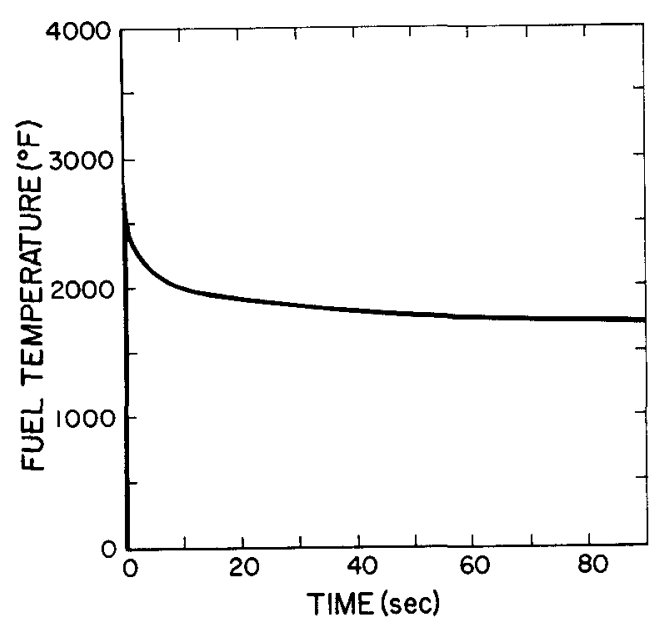

b. Fuel Temperature

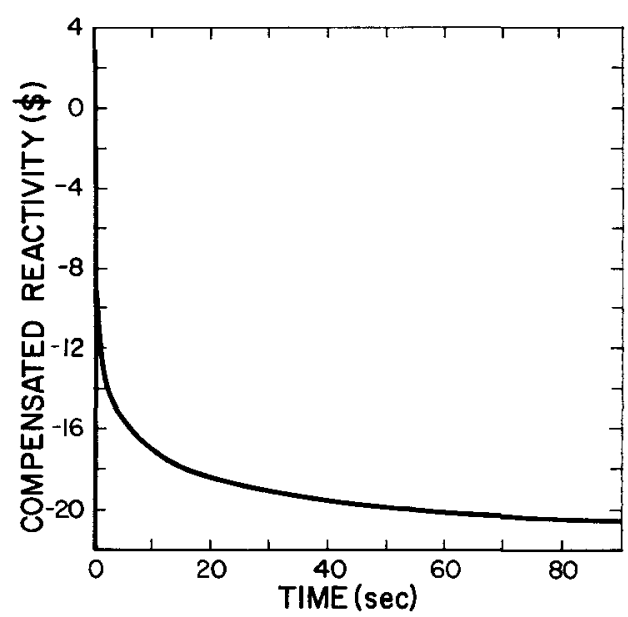

c. Compensated Reactivity

$z$
$p$
$p$
1
$w$
$w$
0
1
1
$\omega$
$\alpha$
$\infty$
$\infty$

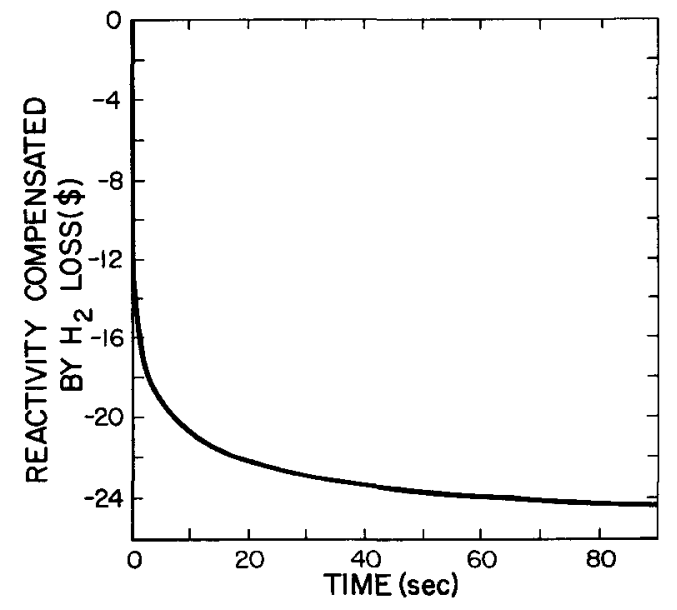

d. Reactivity Compensated by $\mathrm{H}_{2}$ Loss

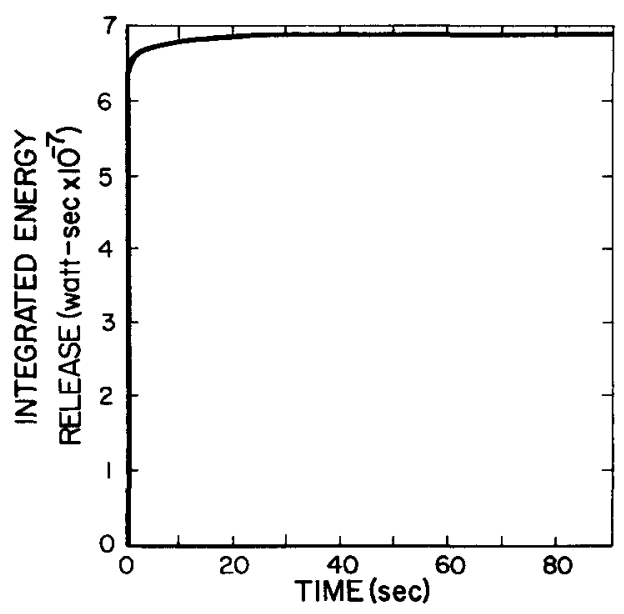

e. Integrated Energy Release

Figure 5. $\$ 5.00$ Ramp at $\$ 100.00 / \mathrm{sec}$ 


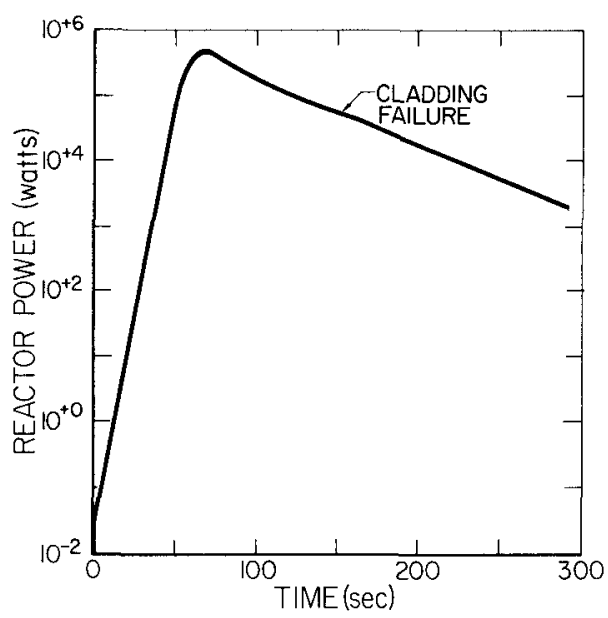

a. Reactor Power

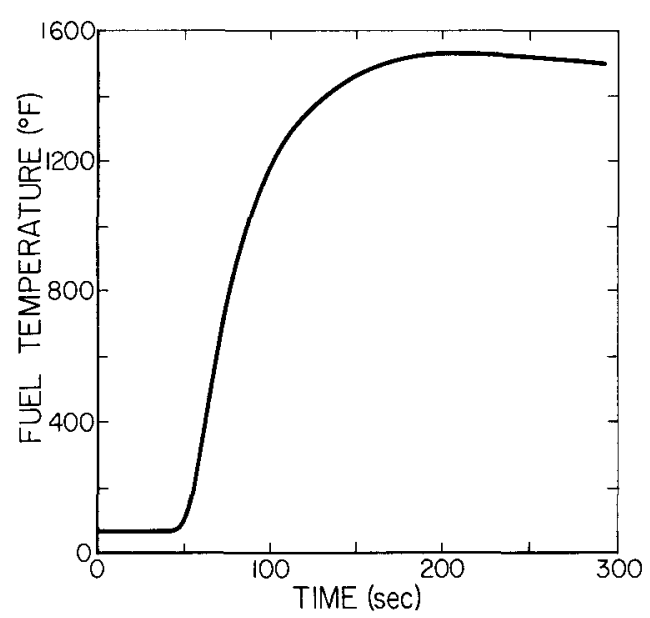

b. Fuel Temperature

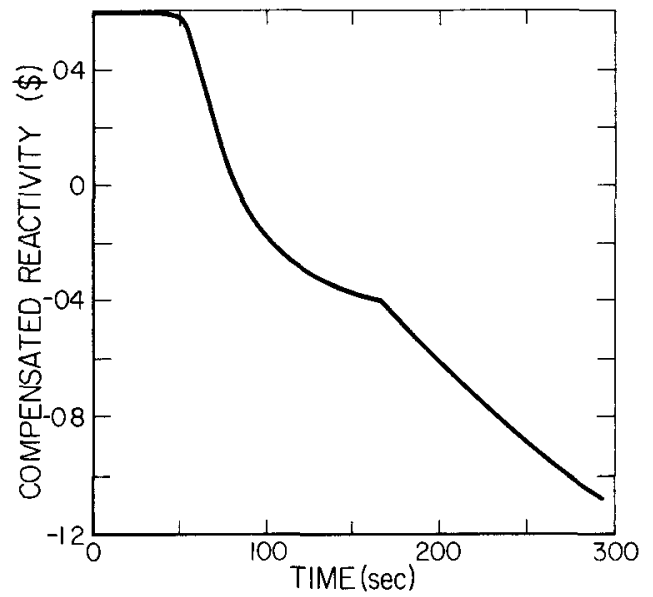

c. Compensated Reactivity

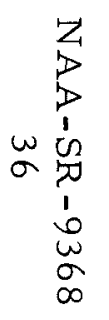

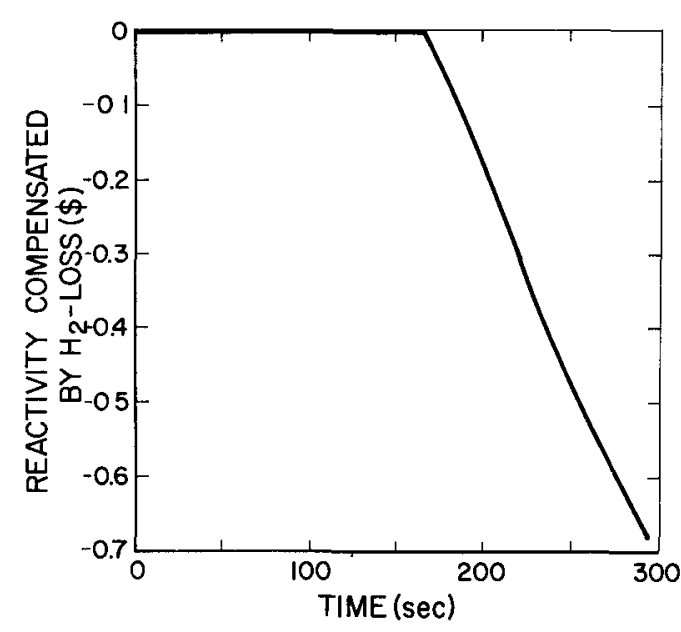

d. Reactivity Compensated by $\mathrm{H}_{2}$ Loss

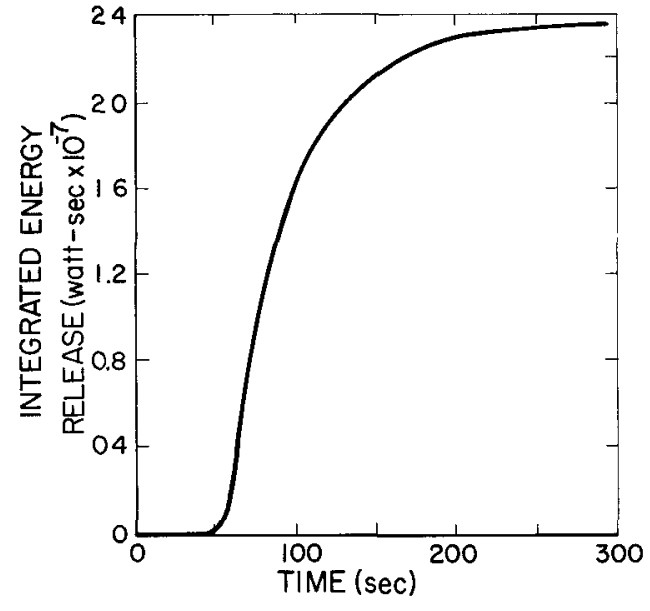

e. Integrated Energy Release

Figure 6. \$0.60 Step 


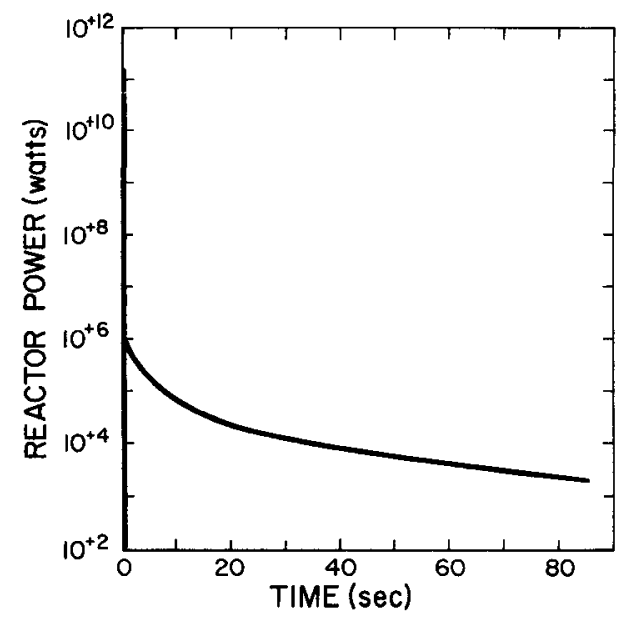

a. Reactor Power

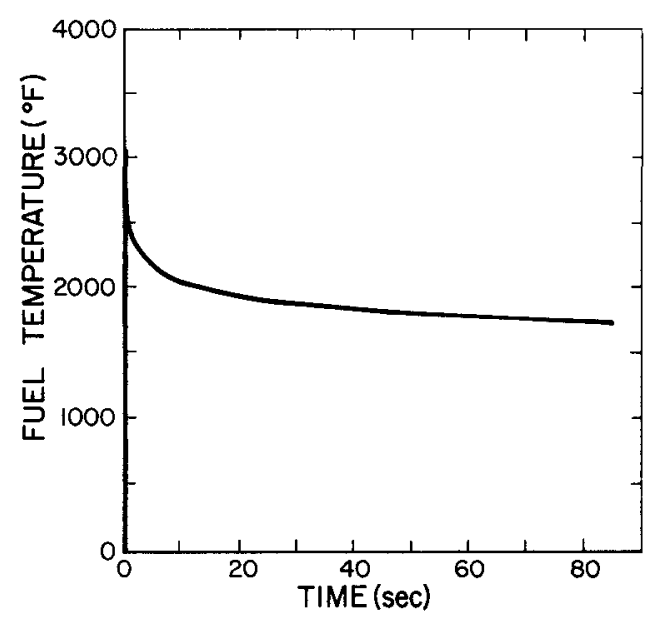

b. Fuel Temperature

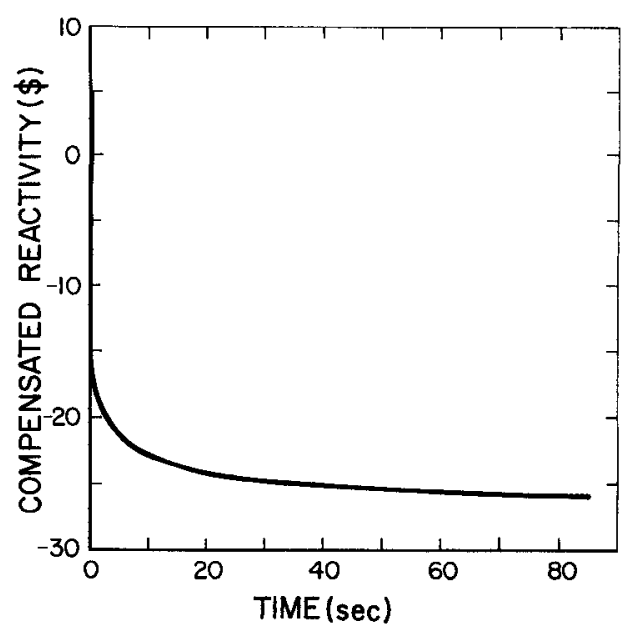

c. Compensated Reactivity

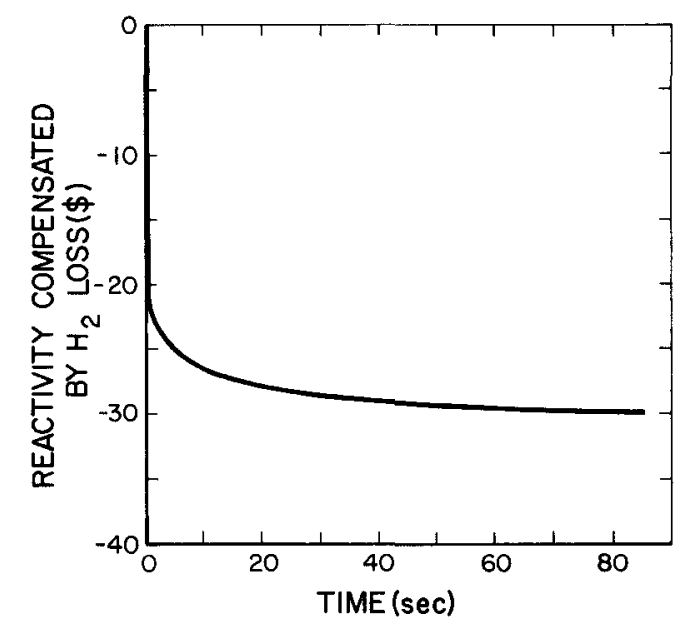

d. Reactivity Compensated by $\mathrm{H}_{2}$ Loss

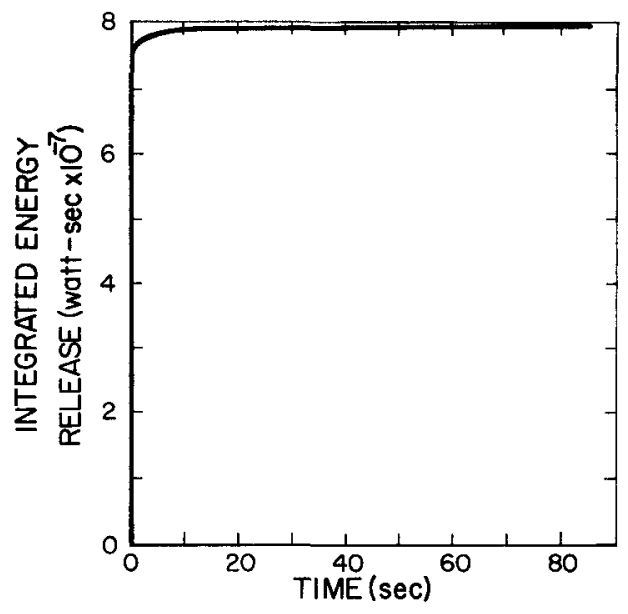

e. Integrated Energy Release

Figure 7. $\$ 5.00$ Step 
Blank page 


\section{REFERENCES}

1. R. V. Meghreblian and D. K. Holmes, Reactor Analysis (New York, McGraw-Hill, 1960) Chapter 9

2. A. F. Henry, "Computation of Parameters Appearing in the Reactor Kinetics Equations," WAPD-142 (December 1955)

3. D. F. Gamble, "The Effect of Reflector-Moderated Neutrons on the Kinetics of the Kinetic Experiment Water Boiler Reactor," Transactions of the American Nuclear Society 3, 1, Paper 11-9 (June 1960)

4. A. A. Wasserman, "A Simple Model for the Effect of Reflected Neutrons Upon Reactor Kinetics," IDO-16606 (July 1960) pp 32-50

5. C. E. Cohn, "Reflected Reactor Kinetics," Nuclear Science and Engineering 13. (1962) pp 12-17

6. E. R. Cohen, "Some Topics in Reactor Kinetics," Second Geneva Conference, Paper 629 (September 1958)

7. J. Miller, "Neutron Kinetics for Reflected Compact Reactors on Short Periods," NAA-SR-TDR-8581 (June 3, 1963)

8. C. E. Cohn and B. J. Toppel, "IBM-704 Codes for Reactivity Step Calculations (RE-126 and RE-135)," ANL-6134 (March 1960)

9. International Business Machines, Inc., Nuclear Computing Technical Bulletin No. 2 (September 1961)

10. J. Miller, et al., "Temperature Coefficients and Spectra in the Hydride Moderated SNAP Reactors," NAA-SR-7140 (December 30, 1962)

11. C. L. Huffine, "Evaluation of Clad Hydrided Zirconium as Solid Moderator," APEX-335-GE-ANPD (November 1956) Secret

12. R. E. Taylor, "Pulse Heating of Modified Zirconium-Uranium Hydrides," NAA-SR-7736 (February 15, 1963)

13. W. J. Tomasch, "Specific Heats of Delta-Phase Zr-H and Zr-D," Physical Review 123, 2 (1951) p 510

14. C. Kittel, Introduction to Solid State Physics (Wiley, 1956) Chapter 6

15. Scalettar, "The Fuchs-Nordheim Model With Variable Heat Capacity," Nuclear Science and Engineering 16, 4 (August 1963) p 459

16. L. R. Blue and M. Hoffman, "Generalized Program for the Numerical Solution of Space Independent Reactor Kinetics Equations," AMTD-131 (January 1963) 
17. R. W. Winson, "BOOMER - A Digital Program for Evaluatıng the Thermal and Kinetics Response of a SNAP 2/10A Reactor," NAA-SR-MEMO-8414 (July 1963)

18. W. B. Green, "A Study of Reactor Kinetics Codes at Atomics International and Their Applicability to SNAP Systems," NAA-SR-TDR-9328 (December 16, 1963)

19. O. D. Seawell, "OSCAI-1: Digital Multi-Channel Nuclear Reactor Transient Simulator Program," AI-MEMO-8296 (March 1963)

20. W. A. Rhoades, "The SNAPKIN-VI Computer Program for SNAP Reactor Kinetics Calculations," NAA-SR-9190 (October 1963)

21. E. R. Cohen, "Some Topics in Reactor Kinetics," Second Geneva Conference on the Peaceful Uses of Atomic Energy, Paper 629 (1955)

22. W. Sangren, Digital Computers and Nuclear Reactor Calculations (John Wiley and Sons, 1960) p 71 